\title{
Effects of subsidising bus travel on the occurrence of road traffic casualties
}

\author{
JONATHAN P NICHOLL, MICHAEL R FREEMAN, AND BRIAN T WILLIAMS \\ From the Department of Community Medicine, University of Sheffield Medical School, Beech Hill Road, Sheffield, \\ S10 $2 R X$
}

SUMmaRY Between 1975 and 1 April 1986, public transport by bus in the metropolitan county of South Yorkshire, England, was increasingly subsidised. Trends in road traffic accident casualties between 1974 and 1983 in all the six provincial English metropolitan counties have been compared in order to examine the possible effect of this unique subsidy on the incidence of road traffic accident $\vec{\omega}$ casualties. During that period the total number of casualties in South Yorkshire did not change $\stackrel{\odot}{\circ}$ significantly compared to the other metropolitan counties. However, the proportion of all casualties $\stackrel{\infty}{?}$ in South Yorkshire who were bus occupants did increase relative to other metropolitan counties, indicating either an increase in the amount of bus travel or a decrease in travel by other modes. There $\overrightarrow{\vec{H}}$ was a large increase in bus patronage in South Yorkshire relative to the other metropolitan counties, ${ }_{0}$ and the conclusion is that it is the transport policy in South Yorkshire which resulted in an actual o increase in distances travelled by bus. Since bus is the safest form of road travel, it is concluded that the public transport subsidy in South Yorkshire has benefited the health of the local population by providing the social amenity of additional travel at the least additional health cost.

At 1 April 1986, the six provincial metropolitan county (MC) authorities were disbanded along with the corresponding Public Transport Executives (PTEs) responsible for the provision of bus and coach services. The Public Transport Executive in the metropolitan county of South Yorkshire has had a cheap fares policy for the last 10 years which also ended as a consequence of the disbanding of the county council. This paper examines whether the public transport policy of South Yorkshire had any detectable effect on the pattern of casualties from road traffic accidents in this area, especially any benefit to the health of the population.

In 1984 road traffic accidents accounted for 5788 deaths in the United Kingdom and roughly another 330000 non-fatally injured casualties. ${ }^{1}$ The corresponding figures for South Yorkshire, with a population of 1.3 million, were 107 deaths and 5700 non-fatal casualties (of which 1 fatally injured casualty and 461 non-fatally injured casualties were bus occupants).

Road travel can be by several different modes of transport, for example, by car, motor-cycle, pedalcycle or bus, and travel by each mode is associated with a different risk of injury (table 1). The total number of road traffic casualties that occur in an area
Table 1 Casualties to persons carried: rates per $10^{9}$ travel kilometres*: 1982

\begin{tabular}{lllll}
\hline & \multicolumn{4}{l}{ Mode of travel } \\
\cline { 2 - 5 } Severity of casualty & Car & PSVt & TWMVt & Pedal cycle \\
\hline Fatal & $5 \cdot 5$ & 0.57 & 130 & 54 \\
Serious & 70 & 18 & 2,260 & 1,039 \\
Slight & 260 & 175 & 5,830 & 4,060 \\
\hline
\end{tabular}

- These rates are based on estimates of the total number of kilometres travelled by persons (not vehicles) by each mode.

† PSV = public service vehicle

\$ TWMV $=$ two wheeled motor vehicles-includes motorcycles, mopeds, scooters

Source: Road Accidents Great Britain 1982. HMSO.

depends then on the total amount of travel undertaken, the distribution of travel between modes (the modal split), and the risk associated with each mode of travel. This in turn suggests that the number $>$ of road traffic casualties could be reduced either by reducing the total amount of travel undertaken, $N$ perhaps by providing facilities such as shops and schools near to sites of residence, thus reducing the $N$

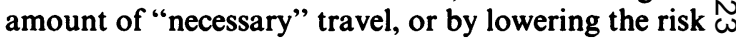
associated with each mode of travel, or by altering the modal split of travel in favour of one of the saferco modes of transport. 
Buses and coaches are the safest form of road transport. A public transport policy that results in increased travel by bus relative to other (more dangerous) modes of transport should have a beneficial effect on road traffic casualties with respect to total distance travelled in an area. In 1975/6 South Yorkshire Public Transport Executive adopted a low fares policy and froze bus fares. This resulted in a large decrease in fare prices in real terms over a ten year period. Between 1975 and 1981 the real fare level rose by $28 \%$ for stage carriage bus services nationally, but it fell by $54 \%$ in South Yorkshire as bus fares were maintained at a constant level in cash terms. ${ }^{2}$ Over the same period, bus miles covered by the other Public Transport Executives fell by $14 \%$ and by $19 \%$ nationally, which contrasts with an increase of $4.5 \%$ in South Yorkshire. Furthermore, in the country as a whole, the number of bus passengers carried declined by $24 \%$ from 1975 to 1983 , and in the other Public Transport Executive areas by an average of $28 \%$, whereas, in the county of South Yorkshire as a whole the number of passengers increased by $5 \%$.

It is difficult to assess to what extent this extra custom has been "caused" by South Yorkshire's policy on public transport subsidy and exactly who the extra passengers are. However, two studies on the effect of the subsidy in South Yorkshire ${ }^{2} 3$ both concluded that the policy had resulted in higher levels of bus use than might otherwise have been expected.

\section{Data and methods}

Data on road traffic accident casualties in the six metropolitan counties (South Yorkshire, Greater Manchester, Merseyside, Tyne and Wear, West Midlands, and West Yorkshire) for the period 1974 83 were obtained from the Stats 19 statistical returns held by the Department of Transport. The Stats 19 records cover all accidents in Great Britain involving personal injury which have come to the attention of the police, and the data include among other information the age and sex of the casualties, the severity of their injuries, and the modes of transport involved. The accuracy of the data is generally good, though some inaccuracies with respect to casualties' ages and injuries have been noted, and there is some under-reporting. ${ }^{4}$

South Yorkshire Public Transport Executive was set up in 1974 and introduced its fares policy in 1975/6. The last full year for which complete road accidents statistics and public transport fare indices were available was 1983, so trends have been studied for the period from 1974 to 1983 inclusive.

It is not possible to determine directly the general trends in travel behaviour and modal split in the metropolitan counties because the necessary information on the total distance travelled by each mode is not available. The National Travel Survey carried out by the Department of Transport was last reported for 1976 and 1978 (results for 1982 were not available) and statistics are not broken down into metropolitan county areas. Consequently, the experience in the other five metropolitan counties was chosen as a control to the situation in South Yorkshire. These metropolitan counties were all large, predominantly urban, provincial conurbations, each of whose public transport policies was governed by one corresponding Public Transport Executive. It was assumed that, in the absence of any effect of public transport policy on road traffic casualties, the trend in road casualties in South Yorkshire would have been similar to that occurring in the combined five metropolitan counties.

The pattern of road casualties over the ten year period 1974-83 in South Yorkshire was compared with that occurring in the other five metropolitan counties combined by fitting log linear and logit models to the data using GLIM. ${ }^{5}$

\section{Results}

An analysis of the possible influence of differences between the metropolitan counties in changes in the structure and size of the population at risk, and of changes in the number of vehicles licensed on the number of road traffic accident casualties showed that these effects could be ignored. For example, the largest difference between any pair of metropolitan counties in the change in their total populations accounted for a difference in the expected annual numbers of fatally and non-fatally injured casualties of only 0.1 and 5.0 casualties respectively. An assessment of changes in casualty reporting levels and in the classification of non-fatal injuries was also made. No evidence of differential changes in reporting levels was found, though there was evidence of differential changes in the classification of injury severity. Accordingly, in all further analyses the casualties' injuries were classified only as fatal or non-fatal.

The number of fatal and non-fatal casualties in each metropolitan county between 1974 and 1983 is shown in figure 1. These data indicate that, relative to the other metropolitan counties, the number of casualties in South Yorkshire was approximately constant during this period and the trend was not atypical.

Figure 2 shows the trend in fatalities by each mode of travel for South Yorkshire and for the other metropolitan counties relative to South Yorkshire. These data provide no evidence that the experience in South Yorkshire in terms of deaths from road traffic accidents has been different from that in the other metropolitan counties over the period studied 


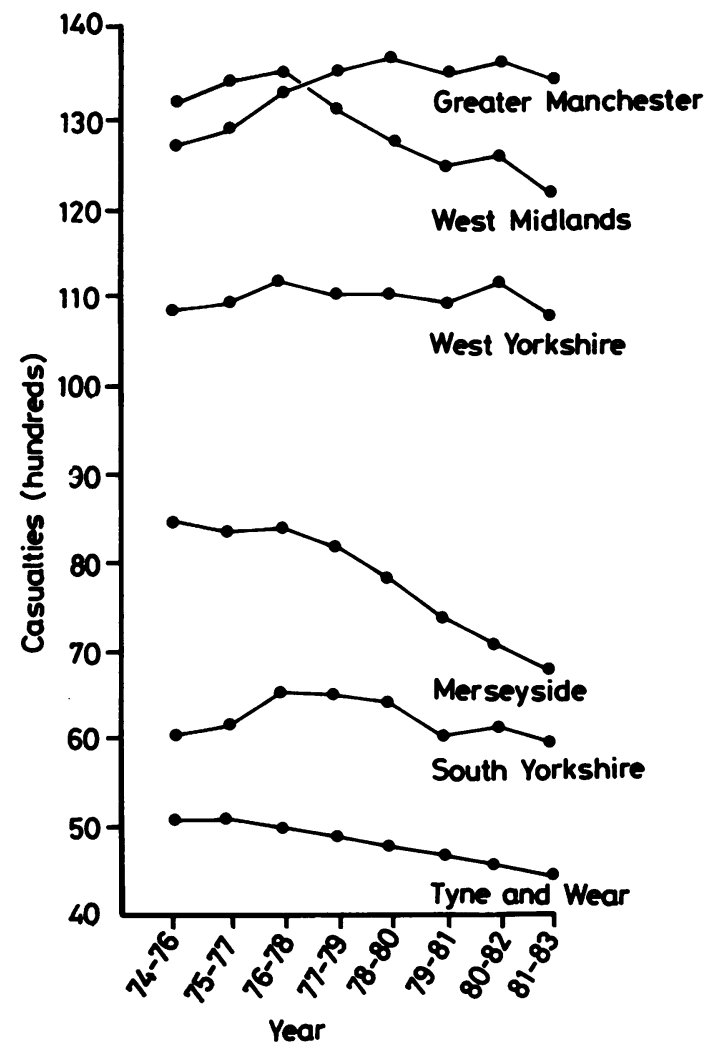

Fig 1 Numbers of casualties of all severities, metropolitan counties, 1974-83. Three-year moving average.

$\left(F_{24,96}=0 \cdot 80, p>0 \cdot 1\right)$. Thus, at least in terms of absolute numbers of deaths from road traffic accidents, the public transport policy adopted in South Yorkshire has had no detectable effect.

Figure 3 shows for different modes of travel the pattern of casualties of all severities occurring in South Yorkshire and the pattern in all the other metropolitan counties relative to South Yorkshire. Although the data as a whole provide no evidence that the trend in South Yorkshire differs from that in the other metropolitan counties $\left(F_{24.96}=0.94, p>0.1\right)$, there is strong evidence $\left(F_{4,20}=4.49, p<0.01\right)$ that the experience in South Yorkshire in terms of casualties to public service vehicle occupants is different from that in the other metropolitan counties. The relative increase in casualties to public service vehicle occupants in South Yorkshire compared with the experience in the other metropolitan counties can also be seen in fig 4 , which shows the trend in the number of casualties to public service vehicle occupants as a percentage of all casualties in South Yorkshire, and
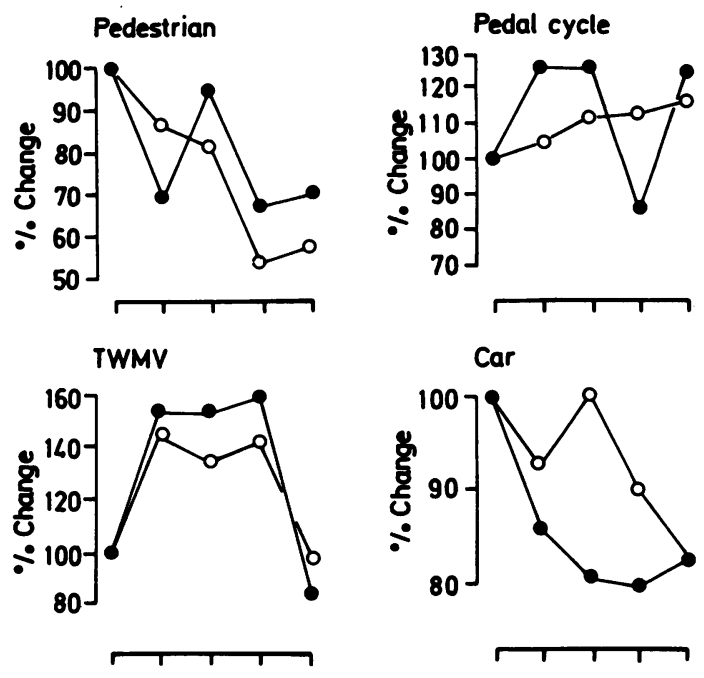

Public service vehicle
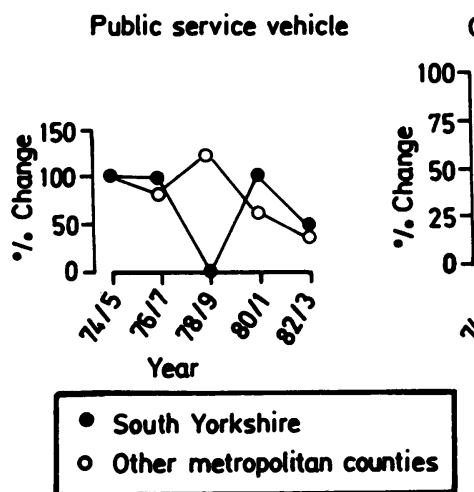

- South Yorkshire
- Other metropolitan counties

Fig 2 Percentage change in numbers of fatal casualties, $b y \overrightarrow{5}$ mode of travel, 1974-83.

the trend in the other metropolitan counties together, relative to South Yorkshire. It can be seen that after an? initial decrease, there is an overall increase in the proportion of public service vehicle casualties in South Yorkshire compared to a decreasing trend in the othero metropolitan counties as a whole.

This difference between the experience in Southe Yorkshire compared with that in the other $>$ metropolitan counties was found to be similar in both? sexes and among different age groups.

The numbers of casualties for each of the other modes were also analysed as a proportion of casualties 0 by all modes excluding public service vehicles. In al $\mathbb{E}$ these cases the data provided no evidence of anyo difference between South Yorkshire and the othere metropolitan counties. 

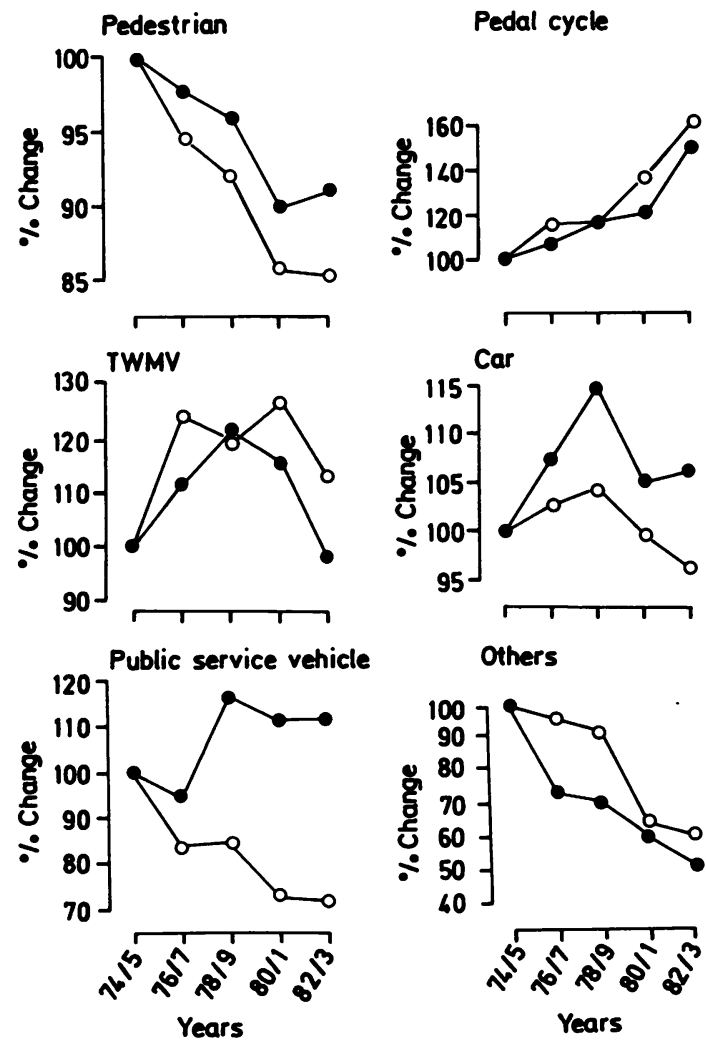

Others

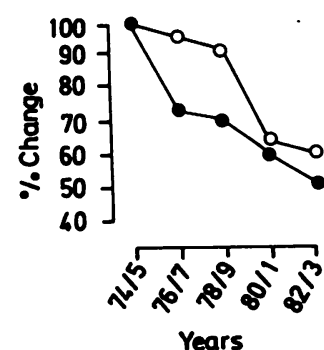

- South Yorkshire

- Other metropolitan counties

Fig 3 Percentage change in numbers of casualties of all severities, by mode of travel, 1974-83.

\section{Discussion}

This analysis shows a similar trend in casualties in South Yorkshire over the past 10 years as in the other metropolitan counties in all respects except that for public service vehicle occupants. Since these data were chosen to examine whether the fares policy in South Yorkshire had affected the road traffic accident casualty situation, and since the increasing differences between South Yorkshire and the other metropolitan counties in respect of public service vehicle casualties shown in fig 4 exactly reflect the increasing fare differential over this period, the conclusion that the South Yorkshire fares policy has caused the observed differences seems reasonable.

This difference is one of increased numbers of public service vehicle casualties both in absolute terms and as

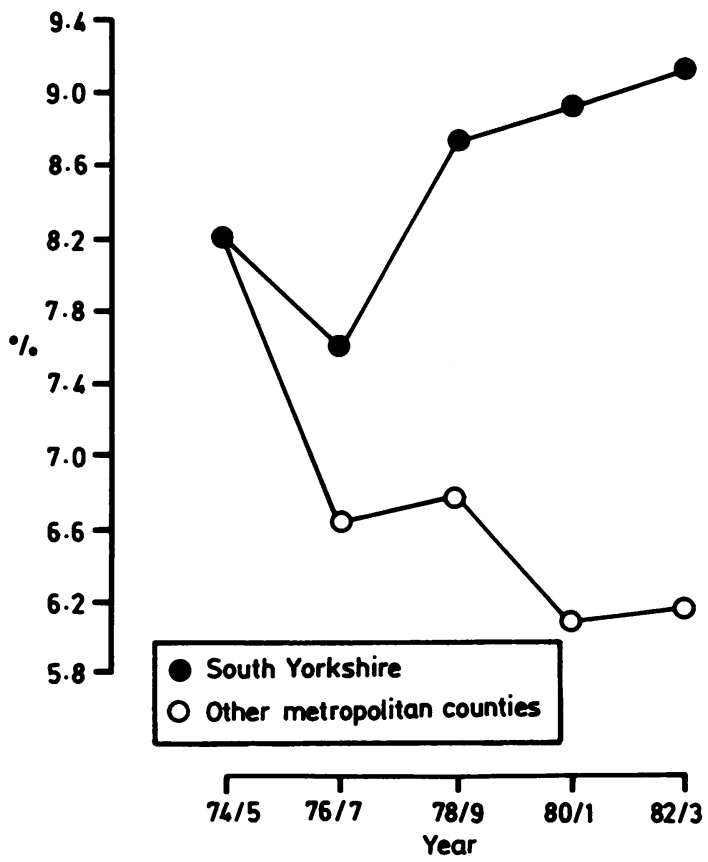

Fig 4 Numbers of casualties to public service vehicle occupants as percentage of all casualties, 1974-83.

a proportion of all casualties relative to other metropolitan counties. Plainly this could have occurred as a result of the fares policy either generating additional (bus) trips or altering the modal split towards bus travel. In the latter case we would expect to see a reduction in the numbers of casualties from other modes in South Yorkshire relative to the other metropolitan counties. Furthermore, since the casualty rates for bus and coach travel are substantially less than for car travel, motor cycle travel and pedal cycle travel (see table 1), we might have expected a substantial reduction. That this has not happened is plain from figure 3 . The conclusion must be that the extra public service vehicle casualties in South Yorkshire, or most of them, have occurred as a result of extra travel being generated, which is undertaken by bus, rather than as a result of a change in the modal split. If this extra travel had been undertaken by modes other than bus, there would have been substantially more casualties than there actually were.

The fares policy in South Yorkshire took the form of a freeze which had a slow cumulative effect on fares and, judging by the proportions of casualties, appears not to have altered the modal split. In contrast, there was a sudden increase in fares in the Greater London 
Council in March 1982 which it is claimed ${ }^{6}$ resulted in an increase in pedal cycle and car and taxi casualties, indicating that the modal split had changed.

Even though the evidence is that the South Yorkshire fares policy resulted in an increase in bus passenger casualties and had no impact on casualties from other modes, it should be remembered that the purpose of public health and other social policies must be to provide services and their derived benefits at the least health cost, and not simply to minimise the health costs alone. To achieve the latter aim one would simply ban all travel. Seen in this light the South Yorkshire fares policy seems indirectly to have provided a clear health benefit to the population by encouraging them to travel, and to travel in the safest possible way-by bus.
References

${ }^{1}$ Department of Transport. Road accidents, Great Britain 1984. London: HMSO.

2 Goodwin PB. Subsidised public transport and the demand for travel-The South Yorkshire example. Gower, 1983.

${ }^{3}$ Hay A. Report to the Transport and Road Research I Laboratory on changes in travel behaviour with special reference to bus use: Sheffield-Rotherham 1972-81 and Manchester Salford 1976-82. (Department of : Geography, University of Sheffield-unpublished).

4 Nicholl JP. The use of hospital inpatient data in the analysis of the injuries sustained by road accident casualties. Supplementary Report SR628. Transport and Road Research Laboratory, Crowthorne. 1980.

5 Baker RJ, Nelder JA. The GLIM system manual, release 3. Oxford: Numerical Algorithms Group, 1978.

${ }^{6}$ Allsop R. Fares and road casualties in London. Report to the Transport and Development Department of Greater $\infty$ London Council, August 1981. Transport Studies Group. $\vec{\circ}$ University College, London. 